QUADERNS DE FILOSOFIA VOL. VI NÚM. I (20I9): 47-58

eISSN: 234 I-3042 DOI: IO.7203/QFIA. 6.I.I 4824

María J. Ferreira Ruiz

CONICET, Universidad de Buenos Aires

\title{
How not to Resist the Natural Kind Talk in Biology
}

Received: 6-7-2018 / Accepted: 17-1-2019

Abstract: After the dawn of the traditional, essentialist view of natural kinds in contemporary philosophy (exacerbated in philosophy of biology by "population thinking"), non-essentialist cluster conceptions of natural kinds have been extensively supported and applied to numerous biological categories. However, salient philosophers have put forward two challenging arguments against cluster kind theories. I argue that, in both cases, discontent with a cluster conception of natural kinds is motivated by tacit and previous assumptions that can be challenged. I conclude that the concerns expressed in the objections do not make good reasons to resist natural kinds talk in biology unless one is willing to share such commitments and assumptions with respect to natural kinds. Ultimately, the discussion can be used to point out that our very expectations regarding natural kinds theories could use a rethink.

Keywords: natural kinds, essentialism, cluster kinds, Boyd, mechanisms.

\section{INTRODUCTION}

CCORding to a traditional CONCEPTION in contemporary philosophy,
natural kinds are defined by necessary and sufficient conditions, which
constitute the kind's essence (PUTNAM I973; KRIPKE I980). Essential properties
are intrinsic features, typically, to be found in a thing's micro-structure. Such
properties are possessed by all and only the members of the kind, and they
must explain why members share other superficial features. For the most
interesting scientific cases, such a definition was hard to achieve, and this
traditional conception received extensive criticism (see BIRD and ToBIN 2015). 
In the philosophy of biology, the most widely discussed case of a natural kind is that of biological species (Boyd 1999; Griffiths i999; Millikan I999; WiLson et al. 2007). However, many authors concerned with species turned against the traditional conception of natural kinds. It was argued that an essentialist conception of species is precluded by or incompatible with the "population thinking" that characterizes modern Darwinian biology (Sober 1980). Mayr argued that the Darwinian theory involves the replacement of an entire mode of thinking in biology, namely essentialism, with an opposite one, namely, population thinking. In his own words:

the populationist stresses the uniqueness of everything in the organic world [...]. All organisms and organic phenomena are composed of unique features and can be described collectively only in statistical terms. Individuals, or any kind of organic entities, form populations of which we can determine the arithmetic mean and the statistics of variation. Averages are merely statistical abstractions, only the individuals of which the population are composed have reality (MAYR I976, 28-9)

The typologist (as Mayr calls it) would regard variation as an illusion, whereas the populationist would take the type to be an abstraction and take variation to be real. From the populationist perspective, then, any essentialist view of natural kinds would be unsuited for biological kinds.

A different conception of natural kinds - one that has been extensively applied in biology — is found in Richard Boyd's seminal work. According to his Homeostatic Property Clusters theory (HPC, hereafter) kinds are not definable in terms of sets of necessary and sufficient conditions, but in terms of a cluster of shared properties and a set of mechanisms responsible for such clustering, both of which are conceived in an open-ended manner. Cluster views of natural kinds have been further developed over the years and they seem to be better prepared to account for classification practices in biology (e.g., to account for species and higher taxa, cell types, homologies, developmental modules, genes, life, or ecosystems).

Nonetheless, and despite the general acknowledgement of the merits of cluster views, compared to a traditional, essentialist conception, some philosophers believe that cluster views are too weak or flexible. More specifically, there are two important objections that, surprisingly, have not been properly analyzed and contested: (a) the explanatory limitation objection and (b) the membership determination objection. My aim in this paper is to dismantle these objections from a naturalistic, anti-essentialist point of view.

I will argue that in both cases, discontent with a cluster conception of natural kinds is motivated by tacit and previous assumptions with respect 
to natural kinds, which involve the aim of a theory of natural kinds and expectations regarding scientific classification systems. I will challenge these assumptions, showing how they are unwarranted, and conclude that the concerns expressed in the objections do not make good reasons to resist natural kinds talk in biology unless one is willing to positively endorse such commitments. My considerations do not rely on peculiarities of any particular biological kind (species or higher taxa, cell types, genes, etc.), but on more general ideas about natural kinds and classifications. Importantly, I will not argue here that there are genuine natural kinds (biological or otherwise). This paper will not contribute to defend natural kind realism. Rather, I aim at undermining two ways of resisting natural kind talk in biology, namely, on the basis of these two objections.

\section{Natural Kinds in Contemporary Philosophy: Micro-essentialism and Property Clusters Kinds}

The topic of natural kinds is one of the most classic topics in metaphysics and philosophy of science. It is a common belief that objects in nature can be classified into different kinds of things, on the one hand, and that natural scientific theories and disciplines talk about these kinds, on the other. Stances on the naturalness of kinds (are there genuine divisions in nature?) range from realism to conventionalism. A realist believes that genuine divisions exist independently of human practices, even if we reflect them incorrectly. In contrast, a conventionalist stands for the idea that all kinds are epistemic construals that reflect our needs and interests (be daily or scientific), with no existence of their own.

The traditional realist conception of natural kinds in contemporary philosophy is mainly due to Saul Kripke (1980) and Hilary Putnam (I973; 1975). According to their view, natural kinds are defined by a conjunction of individually necessary and jointly sufficient conditions, which constitute the kind's essence. Essential properties are intrinsic features, typically, to be found in the thing's micro-structure. Such properties are possessed by all and only the members of the kind, and they must explain why members share other superficial features. Essential properties also explain one of the most salient features of natural kind categories in the traditional view: their projectibility. Traditionally, natural kinds are categories used in explanation and prediction (sometimes expressed in the requirement that they must feature in scientific laws). A well-known example discussed by Kripke is gold. Having the atomic number 79 is an essential property of gold, which explains its 
other microchemical or phenomenic properties. Something similar to gold in superficial respects (color, for example) but which lacks the property of having the atomic number 79, would not be gold. Putnam argues for similar microessentialistic intuitions regarding natural kinds with his famous Twin Earth thought experiment (Putnam 1973; 1975).

Philosophers of the special sciences soon began to criticize the traditional view of natural kinds (for a review of the different criticisms, see BIRD and ToBIN $2015)$. For the most interesting scientific cases, a definition in terms of necessary and sufficient conditions was hard to achieve, and micro-structuralism, as the thesis that kinds can be individuated solely in terms of their microstructural properties, was also put into question. Chemical species and substances and biological species were essentialist philosophers' preferred examples for a long time. Yet, philosophers of chemistry have argued that chemical species and substances are not correctly captured by the essentialist view of natural kinds (Needham 2000; 20i i; van Brakel 2005; Ruthenberg 20i2). Quite the same happened in the philosophy of biology. Several authors concerned with biological species also turned against the traditional view and argued that an essentialist conception of species is precluded by the "population thinking" that characterizes modern evolutionary biology. The upshot seemed to be that any essentialist view of natural kinds was going to be unsuited for biological kinds (MaYr 1966; 1976; see also Sober 1980). Objections against the traditional essentialist view of natural kinds were not only motivated by a general rejection of natural kind talk in biology altogether (such as the view that species are spatio-temporally extended individuals rather than kinds, cf. GHISELIN I974 and Hull 1978). Rather, this traditional conception was contested even by advocates of the natural kindhood of biological species (cf. references below).

A different realist view of natural kinds was put forward by Richard Boyd (I99I; 1999) and further developed by others (for example Millikan I999; Griffiths I999; Wilson, Barker and Brigandt 2007; Slater 201 5), this is, the homeostatic property cluster theory (HPC, hereafter). This view of natural kinds shares an important characteristic with the traditional one, apart from the realist stance. From the point of view of their role in scientific practice, HPC-kinds and traditional kinds stand on an equal footing. However, there are important ways in which HPC theory introduces novel ways of thinking about natural kinds. First, in HPC theory, similarity is nonperfect. Members of a HPC-kind do share some properties, but there is no property or set of properties that can be said to be necessary and sufficient for kind membership. The cluster of properties is conceived in an open-ended manner. Thus, HPCkinds are not definable in terms of sets of necessary and sufficient conditions, as in the Kripke/Putnam view. 
But members of a natural kind in the HPC sense are not just imperfectly similar entities. If this was the case, the inductive power of natural kinds would be something of a miracle. HPC-kinds are projectible categories in virtue of sharing homeostatic mechanisms. These mechanisms are causally responsible for the co-occurrence (clustering) of properties and grant their non-accidentality: entities are not similar just because; they are similar by virtue of common mechanisms that tend to maintain certain properties together, or because the instantiation of some properties favor the instantiation of others. In sum, HPC-kinds are defined and individuated by (i) the property cluster and (ii) the set of underlying homeostatic mechanisms responsible for the former.

Another salient feature of HPC theory is that it is compatible with change. Both the property cluster and the set of underlying homeostatic mechanisms may change along with changes in environmental contexts, so HPC-kinds are not immutable. Such a tolerance to change opens up the possibility of kinds with vague boundaries, which makes the theory especially attractive to account for the changing nature of biological phenomena.

There is a widespread understanding that HPC theory (or other philosophical views with the main characteristics of HPC) is better prepared to deal with classification practices in biological sciences, as shown by the multiple applications of it in the philosophy of biology literature. Apart from species (Boyd I988; I989; I99I; I999A; I999B; Keller, Boyd \& Wheeler 2003; WilsON 2005; Wilson, BARKER and BRIgANDT 2007), other biological categories argued to constitute cluster kinds include higher taxa (RIEPPEL 2005B), cell types (Wilson, Barker and Brigandt 2007; Slater 20i3), ecosystems (Slater 20i8), life (Diéguez 20 i3; Ferreira Ruiz and Umerez 20I 8), homologies (RIEPPEL 2005A; BRIGANDT 2002), developmental modules (Rieppel 2005A), and genes (Wilson, Barker and Brigandt 2007). Yet some philosophers have criticized HPC (and/or related views). In the next section, I will consider two objections against cluster kinds and suggest how they can be countered.

\section{How Not to Resist the Natural Kind Talk in Biology}

The merits of the cluster notions are generally acknowledged, but for some there is a high price to pay for such merits. Here, I will address two objections: explanatory limitation and membership determination. Countering these objections shows at least two ways in which one should not resist the natural kind talk in biology. 


\subsection{The Explanatory Limitation Objection}

In analyzing different conceptualizations of life, Mark Bedau (20I4; 2007) recognizes that a property-cluster approach to living systems neatly explains the existence of borderline cases and why life comes in degrees, difficulties faced by those attempting to define life. However, he also states that cluster views are unsatisfying insofar as they fall short of some explanatory potential that they should bear. Bedau finds the "weakness" of the cluster approaches in the fact that "explanations end too quickly". He writes:

The view does not explain why certain properties in the cluster are significant and other properties are not (...). The cluster conception cannot explain why life is characterized by one cluster of properties rather than another. The dimensions of the cluster of properties associated with living organisms is simply accepted as a contingent empirical fact. Those who expect some further explanation for life's characteristic properties will find the cluster conception of life unsatisfying (BEDAU 2014, 18, emphasis added)

The objection sounds seriously challenging at first glance, but I want to show that it conflates two different questions and misses the important one. I suggest that the question "Why is a kind characterized by certain properties rather than by others?", while extremely important to other contexts, is not relevant for evaluating the success or failure of natural kind theories, either essentialistic or otherwise. For an essentialist, since a kind is characterized by its essential properties, and once we've found the essence of a kind, it makes little sense to ask further "why is this rather than that the essence of this kind?" By definition, it could not have been differently (otherwise, this would not really count as an essence). Or, perhaps worse, the only possible answer would be circular: "because that's its essence". From the anti-essentialist perspective, the fact that a kind is characterized by certain properties rather than by others (which could be rephrased as the fact that one cluster of properties is maintained by certain homeostatic mechanisms rather than another), while not a matter of definition, could only be regarded either as a brute fact of the universe or as a matter of divine intention. This might sound uncomfortably problematic, but we do seem to accept this type of situation. For example, we would rarely question why the speed of light is 299,792,458 meters per second rather than a different one (LANGE 2002, ch. 4.3). So, it might be the case that a cluster approach cannot offer an answer to this type of questions, but neither can other types of theories, and this is probably unachievable. Bedau's question shouldn't be used to evaluate natural kind theories because if it were, no theory would pass the test. This is a situation that could lead us to reject essentialistic and anti-essentialistic views of natural kinds altogether, or could point to something 
else. In fact, we might as well wonder whether this was the pertinent question - again, from the point of view of a philosophical theory of natural kinds-

I contend that the crucial question from the point of view of the philosophical problem of natural kinds, and how are natural kind theories evaluated, is how we distinguish natural kinds from non-natural kinds. Whereas natural kind theories do not aim at answering Bedau's question, they do offer criteria to answer this one. It is interesting to notice how can both be easily conflated under an essentialist viewpoint: natural kinds are distinguished from non-natural kinds because objects belonging to a given natural kind share essential properties, and those are precisely the properties that characterize the kind. But what is even more interesting is that both questions seem to collapse in Bedau's objection too. Recall he suggests that the cluster approach is flawed because it fails to answer the question as to why a kind is characterized by certain properties rather than by others. If we agree that the key question a theory of natural kinds must pursue is that of how to distinguish natural kinds from non-natural kinds, then, one would also see that his expectation that a cluster approach to natural kinds should, in order to succeed as such (i.e., in order to be able to account for the second), also answer the first question, entails a conflation of the two questions ${ }^{1}$.

Of course, I do not mean to deny that there must be an explanation for the fact that, among the multiple properties that characterize living things, some are more common than others. Rather, my point is that this question cannot be properly addressed from the philosophical point of view of identifying natural kinds, where the problem is how to distinguish natural classifications from non-natural ones. In fact, the first question is independent of this latter issue and calls for biological theories, models, generalizations, and hypotheses (SOBER 1992, 763). If we could expect the kind concept of living systems to answer questions such as "why do most living things reproduce?", or "why do replicating entities usually undergo evolution?" by itself, then what should we need biological science for? Biology must explain the occurrence and co-occurrence of properties of living things, but this is too much to ask of a natural kind concept.

\subsection{The Membership Determination Objection}

The second objection I consider here has to do not with the explanatory scope of cluster theories when already facing a classification (this is, provided the sorting has been done), but with the sorting itself. More specifically, it

\footnotetext{
${ }^{1}$ Not in the sense of the failure to distinguish them as distinct questions, but to pick out that which expresses the aim of a NK theory.
} 
states that HPC theory (and, likely, any other cluster view) fails to offer solid criteria to fix kind membership. This is due to the fact that both the property family and the underlying homeostatic mechanisms are defined in an openended manner, so that both may in principle change (REYDOn 2009). Thomas Reydon claims that "HPC theory, then, can only account for kinds whose extensions have already been fixed independently by other means" (2009, 729).

First, Boyd was not unaware of this, and he rather acknowledged that determining membership can be difficult in some cases. However, he didn't see this "necessary indeterminacy", as he called it (see BoyD I99I, 141-2), as a serious problem for his HPC theory. Other cluster views do not take this to be a problem either (see SLATER 201 5). Then, from what point of view is this really a problem?

It will certainly be a serious difficulty for those who believe that a theory of natural kinds must fundamentally provide us with criteria to fix membership, an idea that might betray essentialistic hidden assumptions. From an essentialist point of view, fixing membership is a very simple thing to do in principle: one only needs to find out whether the item instantiates the kind's essence, provided that said essence has been identified. Shortly, for any given object $\mathrm{x}$, a given kind $\mathrm{K}$ and an essence $\mathrm{E}$ of $\mathrm{K}, \mathrm{x} \in \mathrm{K} \leftrightarrow \mathrm{Ex}$. Faced with the challenge of identifying essences in the first place, determining membership for a given object is arguably the lesser problem. Nonetheless, the very demand that a theory of natural kinds alone provides with infallible membership determination criteria might be itself an essentialist requirement, as essences are meant to play precisely this role.

It might be true that cluster approaches rely on some independent criteria for membership determination, which are far from agreed-upon for the most part in biological classifications. However, the question is, again: is this a reasonable expectation for natural kind theories? Aren't we assuming (even if implicitly) the requirements self-imposed by an essentialist view of natural kinds? From an anti-essentialist point of view, the argument against cluster kind theories cannot be that these fail to offer reliable criteria to determine membership themselves, as this would amount to claiming that non-essentialistic approaches to natural kinds fail for not being essentialistic! And this wouldn't be fair.

I believe that there are two unwarranted assumptions behind this second objection. First, that no classification system can be said to be natural if it fails to classify things in a "black or white", unambiguous, and definitive manner, insofar as this seems to be a consequence of adopting a cluster approach. And we lack a non-essentialistic argument to support this assumption. Secondly, that any approach to natural kinds that does not enclose or entail membership 
determination criteria by itself will fail to be a proper theory of natural kinds. Cluster approaches in fact do not set out to provide an algorithmic procedure to determine membership, because they refuse to foreground one or a few properties as essential to biological classifications. Rather, they aim at providing a general framework for identifying natural kinds as opposed to arbitrary or mind-dependent groups of things. I see no reason to believe that determining membership in a clear-cut, "yes or no" manner is a requisite to achieving the former goal and therefore, no reason to believe that both things are to be found in a theory of natural kinds. Rather, I contend that the aim of any theory of natural kinds is not so much to be able to fix membership, but to be able to distinguish natural kinds from non-natural kinds in the first place. If the greatest aim of a theory of natural kinds (and the minimum we must expect it to provide for) is rather some criteria with which one can distinguish natural kinds from arbitrary groupings of things, and if cluster theories convincingly achieve this goal, then we need not insist on the membership determination worry. Besides, determining membership is to a great extent a scientific task and should not be left for philosophy alone to settle.

\section{Final Remarks}

The natural kind talk in biology (and elsewhere) can be resisted from very different points of view. For example, it can be resisted from the more general scientific anti-realism. If science, generally, is not in the business of pursuing truth (or approximations to it), it is not in the business of pursuing natural classification systems in particular, either. Yet someone endorsing such a stance would not bother discussing the peculiarities and details of cluster views of natural kind (being these realistic in character). Perhaps more interesting and challenging, if one has at least minimal realistic intuitions, are those objections that do not stem from a generalized rejection of natural kinds, such as the ones I have addressed here. The objections examined in section 3 are only relevant if one is not previously committed to the view that a natural kind theory must offer empirical explanations, or to essentialism, or to a generalized anti-realism regarding scientific classifications. It is for those who are not endorsing such stances that I have tried to dismantle the membership determination objection and the explanatory limitation objection. But if this is not the case, then this is not the appropriate way to resist the natural kind talk in biology —and cluster theories of natural kinds should be argued against in a different way-.

By no means are the arguments herein meant to support a generalized cluster view of natural kinds. In fact, it does not follow from my discussion 
of the two objections that a cluster approach to natural kinds is the right way to go. It can still be the case that cluster theories face other, more compelling issues that the alleged pitfalls we have examined. Rather than defending cluster views per se, my aim was to undermine particular objections raised against them and argue that if cluster theories can be resisted, it is not on the grounds of such objections.

The ultimate moral to be drawn from the analysis of the objections minds our very expectations from philosophical theories of natural kinds: what is it that such a philosophical theory must provide? And this question needs to be properly contextualized, this is, by reference to more general philosophical stances (as scientific essentialism, scientific naturalism, or scientific antirealism). From an anti-essentialist point of view, rather than considering that the "permissiveness" of cluster approaches must be deemed unacceptable, we might as well revise our own expectations regarding natural kinds.

\section{Acknowledgements}

Thanks to Laura Nuño de la Rosa and Cristina Villegas, organizers of the Eighth Philosophy of Biology and Cognitive Sciences Research Workshop in Madrid. I also thank María Cerezo and Vanessa Triviño. Founding for this work was provided by Ministerio de Economía y Competitividad de España (grant FFI2013-47849-P, "Contemporary Questions in the Metaphysics of Biological Sciences") and CONICET Argentina. 


\section{REFERENCES}

Bedau, M. 20 I 4, "The Nature of Life", S. Luper (ed.), The Cambridge Companion to Life and Death, Cambridge: Cambridge University Press, 13-29.

Bedau, M. 2007, "What is life?", S. Sarkar \& A. Plutynski (ed.), A Companion to the Philosophy of Biology, New York: Blackwell, 455-71.

Bird, A. \& Tobin, E. 20I5, "Natural Kinds", E. Zalta (ed.), The Stanford Encyclopedia of Philosophy (Spring 2015 Edition). URL = http://plato.stanford. edu/archives/spr2015/entries/natural-kinds/

Boyd, R. I999A, "Homeostasis, Species and Higher Taxa”, R. Wilson (ed.), Species: New Interdisciplinary Essays, Cambridge: The MIT Press, 141-85.

BoyD, R. І999в, "Kinds, complexity and multiple realization", Philosophical Studies 95: 67-98.

BoyD, R. I991, "Realism, Anti-Foundationalism, and the Enthusiasm for Natural Kinds", Philosophical Studies 61: 127-48.

Boyd, R. I989, "What realism implies and what it does not", Dialectica 43, 5-29.

Boyd, R. I988, "How to be a moral realist", G. SAYre-McCord (ed.), Essays on moral realism, Ithaca \& London: Cornell University Press, 181-228.

Brigandt, I. 2002, "Homology and the origin of correspondence", Biology and Philosophy 17 (3): 389-407.

Diéguez, A. 2013, "Life as a Homeostatic Property Cluster", Biological Theory 7 (2): 180-6.

Ferreira Ruiz, M. \& Umerez, J. 20 i 8, "Dealing with the changeable and blurry edges of living things: a modified version of property-cluster kinds", European Journal for Philosophy of Science 8 (3): 493-518.

Ghiselin, M. I974, “A Radical Solution to the Species Problem”, Systematic Zoology 23: 536-44.

Griffiths, P. I 999, "Squaring the Circle: Natural Kinds with Historical Essences", R. A. Wilson (ed.), Species: New Interdisciplinary Essays, Cambridge: MIT Press, 209-28.

Hull, D. I978, "A Matter of Individuality", Philosophy of Science 45: 335-60.

Keller, R. A.; Boyd, R. N. \& Wheeler, Q. D. 2003, "The illogical basis of phylogenetic nomenclature", Botanical Review, 69: 93-110.

Kornblith, H. 1993, Inductive Inference and Its Natural Ground, Cambridge, Massachusetts: MIT Press.

Kripke, S. I980, Naming and Necessity, Cambridge: Harvard University Press.

Lange, M. 2002, An Introduction to Philosophy of Physics: Locality, Fields, Energy and Mass, Oxford: Blackwell Publishing. 
MaYr, E. I966, Animal Species and Evolution, Boston: Harvard University Press. MaYr, E. 1976, Evolution and the Diversity of Life, Cambridge: Harvard University Press.

Millikan, R. I999, "Historical Kinds and the Special Sciences", Philosophical Studies 95: 45-65.

Millikan, R. 2000, On Clear and Confused Ideas, Cambridge: Cambridge University Press.

Needham, P. 2000, "What is water?", Analysis 60: 13-21.

Needham, P. 20 i i, "Microessentialism: What is the argument?", Noûs 45: 1-21.

Putnam, H. I973, "Meaning and Reference”, Journal of Philosophy 70: 699-711.

Putnam, H. I975, “The Meaning of 'Meaning”, Minnesota Studies in the Philosophy of Science 7: 215-71

Reydon, T. 2009, "How to Fix Membership: A Problem for HPC Theory and a Solution", Philosophy of Science 72: 724-36.

Rieppel, O. 2005A, "Modules, kinds, and homology", Journal of Experimental Zoology (Molecular and Developmental Evolution) 304B: 18-27.

Rieppel, O. 2005в, "Monophyly, paraphyly, and natural kinds", Biology and Philosophy 20: 465-87.

Ruthenberg, K. 2012, "What is water? Some philosophical considerations", H. P. Hahn, K. Cless \& J. (ed.), People at the Well: Kinds, Usages and Meanings of Water in a Global Perspective, Soentgen, Frankfurt: Campus Verlag, 65-78.

Slater, M. 20I3, "Cell Types as Natural Kinds", Biological Theory 7: 170-9.

Slater, M. 20 I 5, "Natural Kindness", British Journal for the Philosophy of Science 66: 375-411.

Slater, M. 201 8, "Anchoring in ecosystemic kinds", Synthese 195: 1487-1508.

Sober, E. I980, "Evolution, Population Thinking and Essentialism", Philosophy of Science 47: 350-83.

Sober, E. I 992, "Learning from Functionalism. Prospects for Strong Artificial Life”, C. Langton, C. Taylor, D. Farmer, \& S. Rasmussen (ed.), Artificial Life II, Massachusetts: Addison-Wesley, 749-65.

van Brakel, J. 2005, "On the inventors of XYZ", Foundations of Chemistry 7: 57-84.

WiLsOn, R. 2005, Genes and the agents of life: The individual in the fragile sciencesbiology. Cambridge: Cambridge University Press.

Wilson, R.; Barker, M. \& Brigandt, I. 2007, "When Traditional Essentialism Fails: Biological Natural Kinds", Philosophical Topics 35 (1-2): 189-215. 